\title{
USO DE CERA DE CARNAÚBA E SACO PLÁSTICO POLIOLEFÍNICO NA CONSERVAÇÃO PÓS-COLHEITA DO MARACUJÁ-AMARELO ${ }^{1}$
}

\author{
WAGNER FERREIRA DA MOTA², LUIZ CARLOS CHAMHUM SALOMÃO ${ }^{3}$ CLÁUDIO RODRIGO LACERDA \\ NERES $^{4}$, GISELE POLETE MIZOBUTSI ${ }^{2}$, LUDMILA LAFETÁ DE MELO NEVES ${ }^{5}$
}

\begin{abstract}
RESUMO - A alta perecibilidade do maracujá-amarelo reduz sua vida de prateleira limitando sua comercialização. Este trabalho teve por objetivo aumentar a conservação pós-colheita do maracujá-amarelo pelo uso de cera e saco plástico poliolefínico. Os frutos, após colhidos, selecionados, lavados e desinfestados com hipoclorito a 1\%, foram submetidos aos tratamentos: 1-imersão em cera de carnaúba (Fruit wax®), diluída na proporção 1:4 (m/v); 2 embalagem em saco plástico poliolefínico com 0,015 mm; 3 associação entre a imersão na cera de carnaúba e embalagem plástica; 4 testemunha, onde os frutos foram imersos em água com hipoclorito a 1\%. Foram feitas análises da porcentagem de perda de matéria fresca, do teor relativo de água na casca, de sólidos solúveis, da acidez titulável, da relação sólidos solúveis/acidez titulável da polpa, das porcentagens de casca e polpa, e da relação casca/polpa. Houve menor porcentagem de perda de matéria fresca ao utilizar os tratamentos 2 e 3 ao longo do período de armazenamento. Entretanto, não houve diferença entre os tratamentos com relação à matéria fresca do fruto, casca e polpa, havendo redução destas variáveis durante o período de armazenamento. Também não houve diferença com relação às porcentagens de casca e de polpa, e relação polpa/casca, sendo que a primeira reduziu, e as duas seguintes aumentaram no armazenamento. Em geral, houve redução dos sólidos solúveis e da acidez.
\end{abstract}

Termos para indexação: Passiflora edulis, atmosfera modificada, perda de massa, pericarpo

\section{USE OF CARNAUBA WAX AND PLASTIC FILM ON POSTHARVEST CONSERVATION OF THE YELLOW PASSION FRUIT}

\begin{abstract}
The high perishability of the yellow passion fruit reduce its postharvest conservation and availability, mainly for "in natura" consumption. This work objectified to increase the postharvest life of the yellow passion fruit by using wax emulsion and plastic film. After harvest, the fruits were selected, washed, disinfested and submitted to the treatments: 1, immersion in Fruit Wax ${ }^{\circledR} ; 2$, packing in plastic film; 3 , immersion in Fruit Wax ${ }^{\circledR}$ and packing plastic film and 4, control, fruits were immerged in water. The fruits were conditioned in trays and stored in ambient conditions. There were smaller percentage of fresh matter loss and larger water relative tenor when using the treatments two and three in the storage course. However there was no difference among the treatments regarding fresh matter of the fruit, peel and pulp having reduction in the course of storage. There was no difference in the relation of peel percentages and of pulp and pulp/peel relationship and the first reduced and following two increased in the storage. In general, there was total soluble solids and acidity reduction.
\end{abstract}

Index Terms: Passiflora edulis, modified atmosphere, loss of mass, rind.

\section{INTRODUÇÃO}

O maracujá-amarelo é um fruto altamente perecível, o que, aliado ao método tradicional de colheita após abscisão da planta (Castro, 1994; Enamorado et al., 1995), o predispõe a um reduzido período de conservação e comercialização. A rápida desidratação do pericarpo ocasiona murcha e torna o fruto pouco atraente para os consumidores. Segundo Kays (1991), a cutícula que reveste totalmente o fruto é incapaz de conter o rápido processo de desidratação após a colheita.

O período de conservação do maracujá pode ser ampliado, desde que se utilizem mecanismos que reduzam as taxas de transpiração e respiração dos frutos, como o uso de atmosfera modificada com uso de aditivos em sua superfície (Silva et al., 1999) e filmes plásticos (Ben-Yehoshua, 1985). A modificação da atmosfera ocorre em função da interação entre o processo natural de respiração do produto e as trocas gasosas através da embalagem ou cera, podendo haver acúmulo de $\mathrm{CO}_{2}$ e vapor de água, e esgotamento do $\mathrm{O}_{2}$, sendo os níveis controlados pelas trocas gasosas através do envoltório utilizado até atingir o equilíbrio, que depende de características, como espessura utilizada e filme, e composição química. Esta técnica tem sido continuamente utilizada como tratamento para prolongar o período de armazenagem de produtos perecíveis, reduzindo perdas e mantendo a qualidade, uma vez que há redução da respiração dos frutos, induzida pela redução da concentração de $\mathrm{O}_{2}$ e aumento de $\mathrm{CO}_{2}$, além de acúmulo de alta umidade relativa, reduzindo, assim, a perda de água por transpiração e, conseqüentemente, o murchamento, a produção e a sensibilidade ao etileno e as reações de oxidação (Ben-Yehoshua, 1985; Peppelenbos et al., 1996; D' aquino et al., 1998; Chen et al., 2000; Fonseca et al., 2000; Amarante et al., 2001; Mota et al., 2003). Entretanto, melhores resultados são obtidos quando há um balanço adequado entre a permeabilidade do filme ou cera aos gases e a respiração do produto, que depende do tipo, da variedade, do peso, do estádio de maturação e da temperatura dos frutos (Awad, 1993; Robertson, 1993). Embora muitos filmes plásticos com diferentes permeabilidades a gases sejam empregados, o polietileno de baixa densidade (PEBD) e o cloreto de polivinila (PVC) são os mais usados para frutos e hortaliças (Zagory $\&$ Kader, 1988). A otimização do uso de revestimento ceroso em frutos envolve seleção do teor e tipo de cera que resulte em máximo nível de benefícios com toleráveis níveis de risco (Banks et al., 1997).

No entanto, os produtos armazenados nestas condições podem passar a respirar anaerobicamente, sofrendo fermentação com acúmulo de etanol, havendo adicionalmente degradação de tecidos, e gerar "off flavor", principalmente se a temperatura aumenta e a permeabilidade do filme não for adequada; por isso, é necessário controlar a temperatura (Chen et al., 2000; D'aquino et al., 1998).

A utilização de cera evidenciou redução da perda de matéria fresca, enrugamento, manutenção da aparência e firmeza, maior acidez e menor amadurecimento de maracujá-amarelo (Silva et al., 1999; Resende et al., 2001; Mota et al., 2002). O uso de atmosfera modificada tem demonstrado bons resultados no sentido de aumentar a conservação do próprio maracujá ( Collazos et al., 1984; Arjona et al., 1994; Mota et al., 2003), de maçã (Lau \& Yastremski, 1991) e de manga

\footnotetext{
' (Trabalho 085-2005). Recebido: 20-05-2005. Aceito para publicação: 17-07-2006.

Professor, Depto de Ciências Agrárias-UNIMONTES, CEP 39440.000, Janaúba-MG. Autor correspondente (wagner.mota@unimontes.br).

3 Professor Adjunto, DFT-UFV, CEP 36571-000, Viçosa-MG.

Mestrando em Fitotecnia, DFT-UFV, CEP 36571.00, Viçosa-MG.

Doutora em Fisiologia Vegetal, DBV-UFV, CEP 36571-000, Viçosa-MG.
} 
(Baldwin et al., 1999; Sousa et al., 2002)

Assim, o objetivo do presente trabalho foi estudar o uso de cera à base de carnaúba e de saco plástico poliolefínico, visando a aumentar a conservação pós-colheita do maracujá-amarelo.

\section{MATERIAL E MÉTODOS}

Os frutos de maracujá-amarelo foram colhidos totalmente amarelos antes da abscisão da planta no pomar da Universidade Federal de Viçosa, Minas Gerais. Em seguida, foram transportados para o Laboratório de Pós-Colheita, onde foram selecionados e lavados em água corrente potável. Após a lavagem, os frutos foram imersos em solução de hipoclorito de sódio a $1 \%(\mathrm{~m} / \mathrm{v})$ para desinfestação superficial e submetidos aos seguintes tratamentos: 1- imersão em cera de carnaúba (Fruit wax ${ }^{\circledR}$, FNT, Campinas, Brasil) com 18 a $21 \%$ de carnaúba, diluída na proporção 1:4 (m/v); 2- embalagem em sacos plásticos poliolefínicos (Cryovac D-955) com 0,015 mm; 3- associação entre a imersão na cera de carnaúba e embalagem plástica; 4testemunha (sem tratamento algum).

Os frutos de cada tratamento foram acondicionados, em grupos de quatro, em bandejas de poliestireno, constituindo a unidade experimental. $\mathrm{O}$ fechamento da embalagem foi feito por intermédio de selamento e aquecimento do filme plástico, que encolheu e aderiu uniformemente à superfície dos frutos e da bandeja. Em seguida, foram armazenados à temperatura e umidade relativa ambiente $\left(20-25^{\circ} \mathrm{C}, 70\right.$ - $85 \% \mathrm{RH})$, monitoradas por intermédio de um termoigrógrafo, e organizados em um delineamento experimental em quatro blocos casualizados, em esquema de parcelas subdivididas, tendo nas parcelas os quatro tratamentos e, nas subparcelas, os períodos de amostragem.

Diariamente, foi feita análise da porcentagem de perda de matéria fresca, onde as bandejas com os frutos foram pesadas em balança eletrônica digital (Digimed), e o resultado foi expresso em porcentagem. A cada quatro dias, foram feitas as seguintes análises: teor relativo de água na casca, segundo a metodologia descrita por Catsky (1974), com o emprego da equação citada por Weatherley (1950); determinação dos sólidos solúveis, utilizando-se de refratômetro de mesa (Atago, modelo N1), após extração e homogeneização do suco dos frutos de cada bandeja, sendo expresso em ${ }^{\circ}$ Brix; acidez titulável, segundo técnica recomendada pela AOAC (1975), titulando-se $5 \mathrm{~mL} \mathrm{de}$ suco do conjunto de frutos de cada bandeja diluído em água, na proporção de 10:1 (v/v), com $\mathrm{NaOH}$ a $1 \mathrm{~N}$, e o resultado foi expresso em porcentagem de ácido cítrico; relação sólidos solúveis/acidez titulável, dividindo-se os valores de sólidos solúveis pelos da acidez titulável.

Os dados foram interpretados por intermédio de análise de variância e de regressão. As médias dos fatores qualitativos foram comparadas, utilizando-se do teste de Tukey, a 5\% de probabilidade. Os modelos dos fatores quantitativos foram escolhidos com base na significância dos coeficientes de regressão, utilizando-se do teste de t de Student, a 5\% de probabilidade, no coeficiente de determinação e no potencial para explicar o fenômeno biológico em questão.

\section{RESULTADOS E DISCUSSÃO}

Foi observado aumento da porcentagem de perda de matéria fresca (PMF) em todos os tratamentos ao longo do período de armazenamento (Figura 1). O filme plástico e a associação da cera e filme plástico foram mais eficientes na redução da PMF, mantendo os frutos com aspecto mais túrgido e com melhores condições de comercialização durante o período de armazenamento, com perdas de 0,86 e $0,81 \%$ após nove dias de armazenagem, respectivamente. Possivelmente, a maior eficiência destes tratamentos ocorreu pelo surgimento de ambiente saturado de umidade no interior da embalagem, condicionando reduzido gradiente de pressão de vapor de água entre os frutos e a atmosfera interna da embalagem, diminuindo e controlando a transpiração dos frutos (Ben-Yehoshua, 1985; Fonseca et al., 2000; Pesis et al., 2000; Mota et al., 2003). Apesar de a cera de carnaúba também condicionar modificação da atmosfera, verificou-se que a utilização adicional da cera nos frutos envolvidos com o filme plástico não reduziu significativamente a perda de matéria fresca em relação à utilização exclusiva do filme plástico. A diluição utilizada da cera, ou seja, na proporção de 1:4 (m/v), pode ter sido elevada e condicionado permeabilidade além do limite que condicionaria efeito aditivo na redução da PMF.

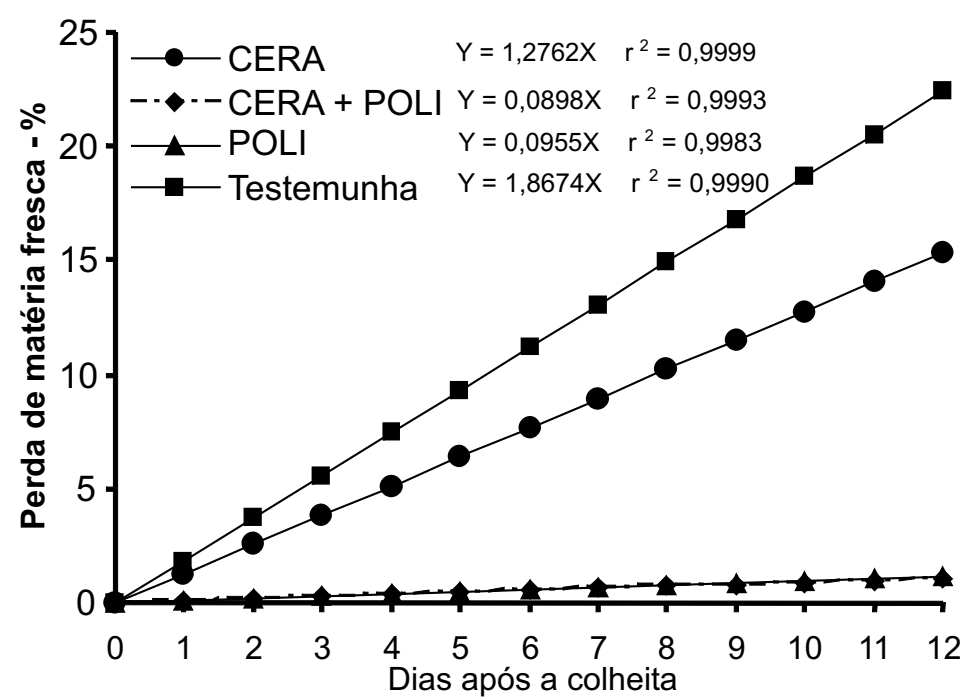

FIGURA 1 - Estimativa da porcentagem de perda de matéria fresca de maracujás-amarelos armazenados em condições ambientes, após revestimento com sacos plásticos poliolefínicos (POLI), imersão em cera de carnaúba (CERA), imersão em cera de carnaúba seguida de embalagem em sacos plásticos poliolefínicos (CERA + POLI) e imersão em água (Testemunha), em função dos dias após a colheita.

Cereda et al. (1976) também verificaram controle da perda de matéria fresca e conseqüente enrugamento ao usar cera parafinada em frutos de maracujá armazenados em condições ambientes. Tendência semelhante foi observada por Mota et al. (2003), ao trabalharem com diferentes ceras e filmes plásticos poliolefínicos, verificando maior eficiência da cera de carnaúba, diluída na proporção 1:4 (m/v), na redução de perda de matéria fresca e murchamento, comparativamente às ceras Sparcitrus ${ }^{\circledR}$, sem diluir, Sunny Side Citrus ${ }^{\circledR}$, diluída na proporção 1:1 (m/v), e menor eficiência em relação ao saco plástico poliolefínico de $0,015 \mathrm{~mm}$ de espessura.

Paralelamente à perda de matéria fresca verificada em todos os tratamentos, observou-se redução linear da massa do fruto, casca e polpa com índice diário de 0,87 g.dia ${ }^{-1}, 0,72$ g.dia $^{-1}$ e 0,16 g.dia $^{-1}$, respectivamente, após a colheita (Figura 2D). A perda de massa da casca é mais significativa que a da polpa. Esta perda explica a redução da porcentagem de casca (Figura 2A), a elevação do teor de polpa (Figura2B) e da relação polpa/casca (Figura 2C), demonstrando que o pericarpo é o tecido mais suscetível à perda de matéria fresca, fortalecendo a evidência de que a maior parte da perda de matéria fresca ocorre no pericarpo (Mota et al., 2003).

Com relação ao teor de água no pericarpo, os frutostestemunha apresentaram redução neste parâmetro ao longo do armazenamento (Figura 3A). A imersão em cera de carnaúba foi mais eficiente que a testemunha na manutenção de maior teor relativo de água até 5,8 dias após a colheita, quando houve elevação do teor relativo de água, atingindo $59,7 \%$. Os frutos embalados em filme plástico e os embalados com posterior imersão em cera demonstraram elevação linear do teor relativo de água. Desta forma, observou-se que os frutos embalados em filme plástico e os tratados com cera mais envolvimento em filme mantiveram maior teor relativo de água na casca, após oito dias de armazenagem, ressaltando a eficiência, principalmente do filme plástico, em reduzir a perda de água. 

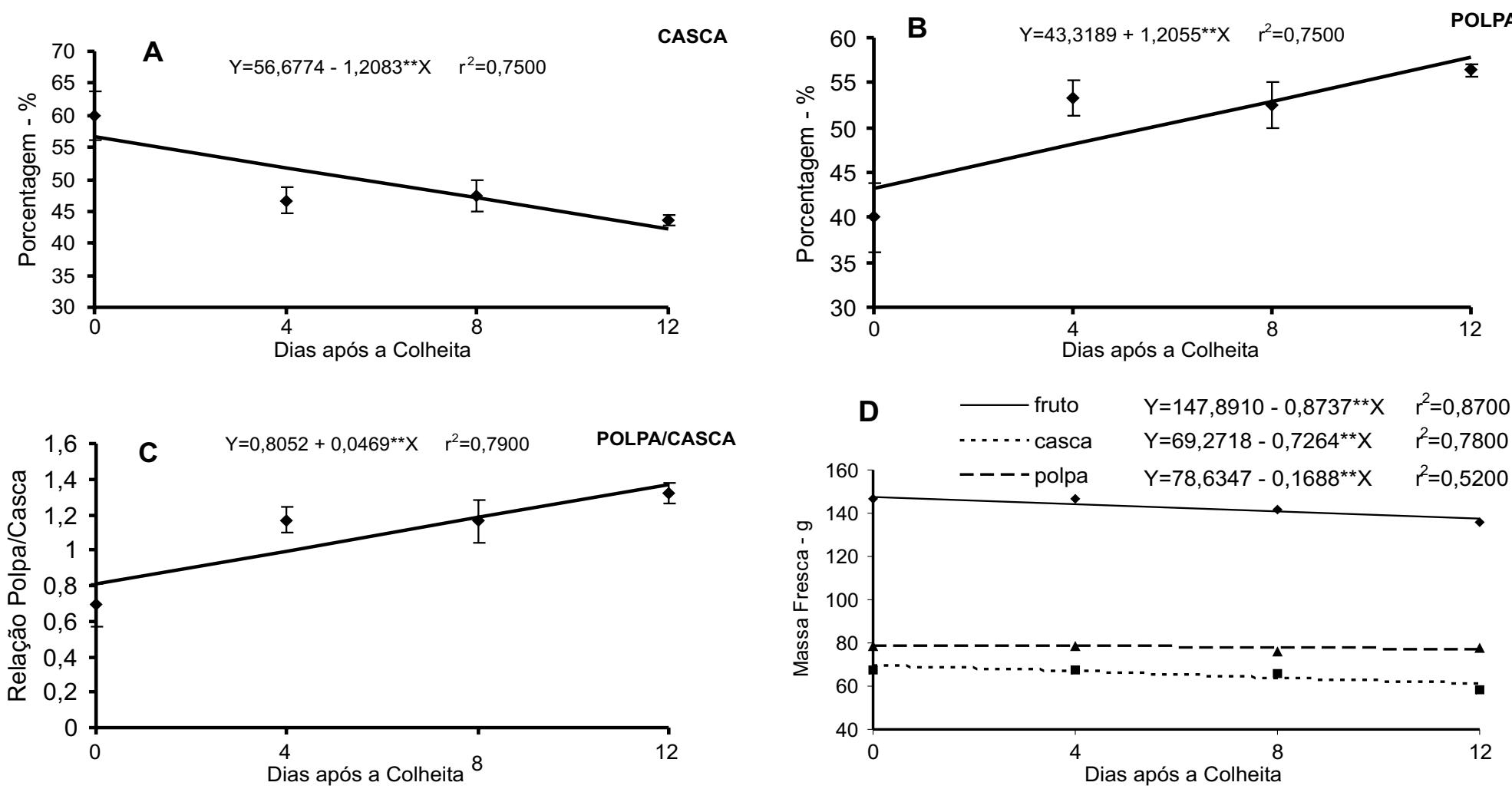

FIGURA 2 - Estimativas das porcentagens de casca (A), polpa (B), relação polpa/casca (C) e massas frescas do fruto, casca e polpa (D) de maracujás, em função dos dias após a colheita.

Houve redução linear dos sólidos solúveis e da acidez titulável (Figura 3, B e C) ao longo do armazenamento, indicando que os açúcares redutores e não-redutores que são substratos orgânicos, foram consumidos pelo processo de respiração de manutenção dos frutos ao longo do período de armazenamento (Kays, 1991; Mota et al., 2003). A redução do teor de sólidos solúveis sugere provável variação negativa no sabor e, conseqüentemente, no "flavor" entre os tratamentos, pois os açúcares, principalmente os redutores, como a frutose, são responsáveis pela sensação de "doçura" dos produtos hortícolas, como o maracujá (Chitarra e Chitarra, 1990; Mattheis e

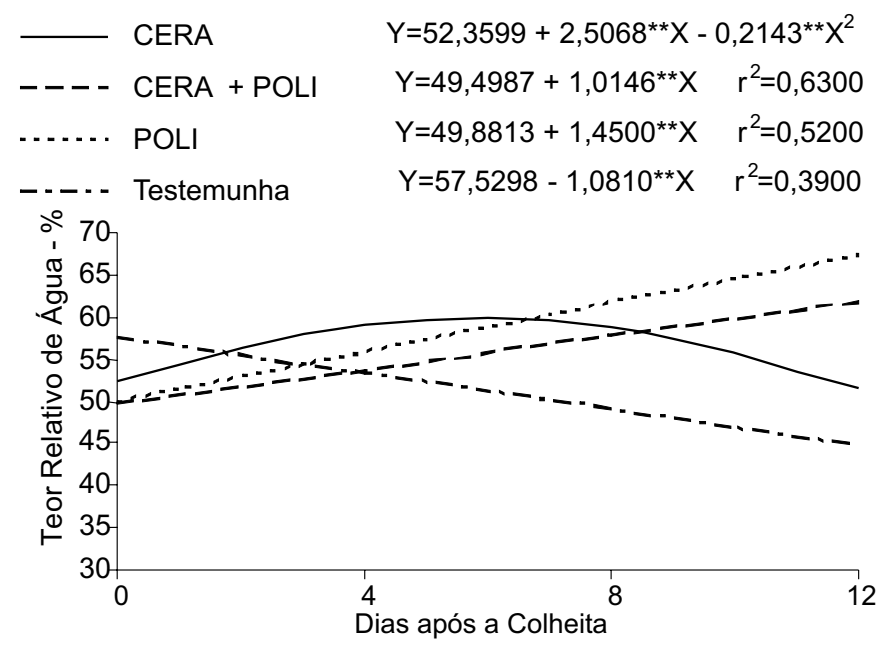

$r^{2}=0,9800$

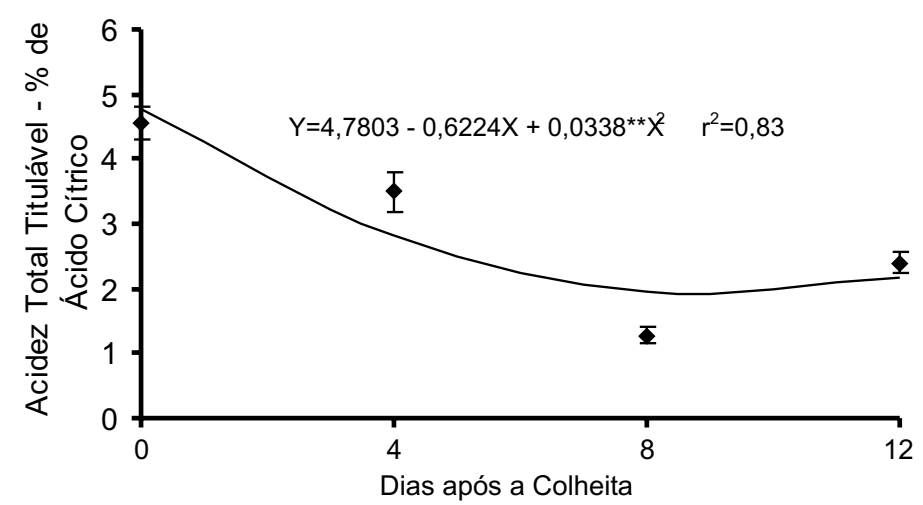

A

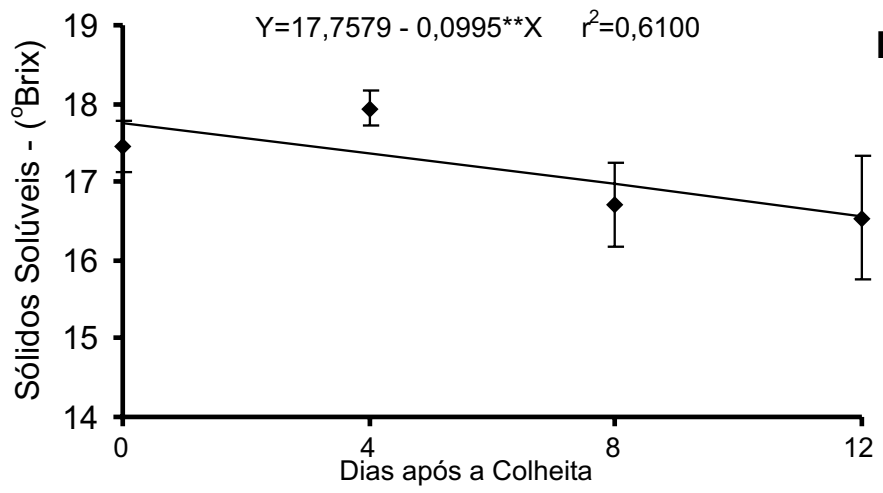

C

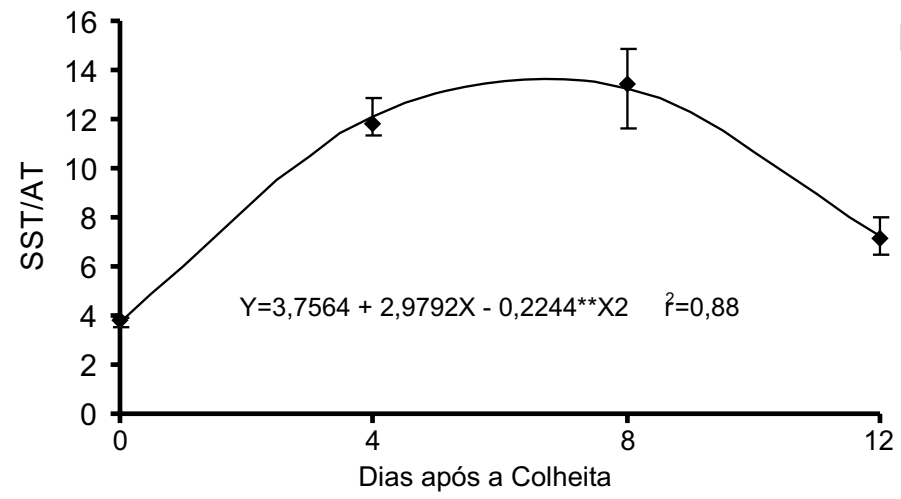

FIGURA 3 - Estimativas do teor relativo de água (A), teores de sólidos solúveis totais (B), acidez total titulável (C) e relação sólidos solúveis totais/acidez total titulável - SST/AT (D) de maracujás, após revestimento com sacos plásticos poliolefínicos (POLI), imersão em cera de carnaúba (CERA), imersão em cera de carnaúba seguida de embalagem em sacos plásticos poliolefínicos (CERA + POLI) e imersão em água (Testemunha), em função dos dias após a colheita. 
Fellman, 1999). Também foi observada redução da acidez titulável ao longo do armazenamento até o oitavo dia, devido à participação dos ácidos como substratos orgânicos durante a manutenção e a senescência ( Kays, 1991; Enamorado et al., 1995; Mota et al., 2003). Segundo Kays (1991), os ácidos orgânicos podem ser oxidados ou convertidos em açucares durante o armazenamento. Entretanto, após o $8^{\circ}$ dia, ocorreu estabilização com leve acréscimo do teor de ácido cítrico, provavelmente em função da não-utilização do ácido como substrato respiratório em conjunto com a elevação da concentração explicada em função da perda de água verificada em todos os tratamentos. A relação sólidos solúveis/acidez titulável aumentou até o $8^{\circ}$ dia após a colheita (Figura 3D), pois, apesar de tanto sólidos solúveis quanto acidez titulável reduzirem neste período, a taxa diária de redução da acidez foi maior com 0,62 eq. gr.dia ${ }^{-1}$ de ácido cítrico, enquanto o teor de sólidos solúveis reduziu a taxa de $0,09{ }^{\circ} \mathrm{Brix} \cdot \mathrm{dia}^{-1}$. A partir do $8^{\circ}$ dia a relação reduziu em função do acréscimo da acidez à taxa de 0,03 eq. gr. de ácido cítrico/dia; no entanto, o teor de sólidos solúveis continuou a reduzir à taxa de $0,09^{\circ} \mathrm{Brix} / \mathrm{dia}$.

\section{CONCLUSÕES}

1) A embalagem de saco plástico poliolefínico e a associação entre a imersão na cera de carnaúba e a embalagem plástica foram mais eficientes na extensão da conservação pós-colheita de frutos de maracujá-amarelo, reduzindo a porcentagem de perda de matéria fresca e conseqüente murchamento, além de manter maior teor relativo de água no pericarpo, mantendo os frutos em boas condições para o consumo.

2) A cera de carnaúba apresentou maior eficiência na conservação pós-colheita em relação à testemunha, em função da menor porcentagem de perda de matéria fresca e manutenção de maior teor relativo de água no pericarpo.

\section{REFERÊNCIAS}

AMARANTE, C.; BANKS, N.H.; GANESH, S. Relationship between character of skin cover of coated pears and permeance to water vapour and gases. Postharvest Biology and Technology, Amsterdan, v.21, p.291-301, 2001.

ARJONA, H.E.; MATTA, F.B.; GARNER JR.; J.O. Wrapping in polyvinyl chloride film slows quality loss of yellow passion fruit. HortScience, Alexandria, v.29, p.295-296, 1994.

AOAC. ASSOCIATION OF AGRICULTURAL CHEMIST. Official methods of analysis of the association of official analytical chemistry. Washington, 1975. 1094p.

AWAD, M. Fisiologia pós-colheita de frutos. São Paulo: Nobel, 1993 $114 \mathrm{p}$.

BALDWIN, E.A.; BURNS, J.K.; KAZOKAS, W.; BRECHT, J.K.; HAGENMAIER, R.D.; BENDER, R.J.; PESIS, E. Effect of two edible coatings with different permeability characteristics on mango (Mangifera indica L.) ripening during storage. Postharvest Biology and Technology, Amsterdan, v.17, p.215-226, 1999.

BANKS, N.H.; CUTTING, J.G.M.; NICHOLSON, S.E. Approaches to optimizing surface coatings for fruits. New Zealand Journal of Crop and Horticultural Science, Wellington, v.25, p.261-272, 1997.

BEN-YEHOSHUA, S. Individual seal-packaging of fruit and vegetables in plastic film - A new postharvest technique. HortScience, Alexandria, v.20, p.32-37, 1985.

CASTRO, J.V. Matéria-prima In: ITAL. Maracujá. Campinas: ITAL, 1994. 267p. (Série Frutas Tropicais, 9).

CATSKY, J. Water content. In: SLAVIK, B. (Ed.). Methods of studyng plant water relations. Berlin: Springer-Verlag, 1974. p.121-131.

CEREDA, M.P.; BRASIL, M.A.M.; LIMA, U.A. Conservação do maracujá-amarelo para consumo "in natura". Acta Horticulturae, Leuven, n.57, p.145-150, 1976.

CHEN, X.; MAARTEN, L.A.T.M.; HERTOG, M.L.A.T.M.; BANKS,
N.H. The effect of temperature on gas relations in MA packages for capsicums (Capsicum annuum L., cv. Tasty): an integrated approach. Postharvest Biology and Technology, Amsterdan, v.20, p.71-80, 2000.

CHITARRA, M.I.F.; CHITARRA, A.B. Pós-colheita de frutos e hortaliças: fisiologia e manuseio. Lavras: ESAL/FAEPE, 1990. 320p.

COLLAZOS, O.; BAUTISTA, A.; MILLAN, B.; MAPURA, B. Efecto de bolsas de polietileno en la conservación de maracuyá (Passiflora edulis var.flavicarpa Degener), curuba (P. mollissima HBK Bailey) y tomate (Lycopersicon esculentum Miller). Acta Agronomica, Palmira, v.34, n.2, p.53-60, 1984.

D’AQUINO, S.; PIGA, A.; AGABBIO, M.; McCOLLUM, T.G. Film wrapping delays ageing of 'Minneola' tangelos under shelf-life conditions. Postharvest Biology and Technology, Amsterdan, v.14, p.107-116, 1998

ENAMORADO, H.E.P.; FINGER, F.L.; BARROS, R.S.; PUSCHMANN, R. Development and ripening of yellow passion fruit. Journal of Horticultural Science, Ashford, v.70, p.573-576, 1995.

FONSECA, S.C.; OLIVEIRA, F.A.R.; LINO, I.B.M.; BRECHT, J.; CHAU, K.V. Modelling $\mathrm{O}_{2}$ and $\mathrm{CO}_{2}$ exchange for development of perforation-mediated modified atmosphere packaging. Journal of Food Engineering, Kidlington, v.43, p.9-15, 2000.

KAYS, S.J. Postharvest physiology of perishable plant products. New York: AVI, 1991.532p.

LAU, O.L.; YASTREMSKI, R. Retention of quality of 'Golden Delicious' apples by controlled-and modified-atmosphere storage. HortScience, Alexandria, v.26, p.564-566, 1991.

MATTHEIS, J.P.; FELLMAN, J.K. Preharvest factors influencing flavor of fresh fruit and vegetables. Postharvest Biology and Technology, Amsterdan, v.15, p.227-232, 1999.

MOTA, W. F.; SALOMÃO, L. C. C.; CECON, P.R.; FINGER, F.L.; PESSOA, A.M. Efeito de Cera sobre a Conservação Pós-Colheita do Maracujá-Amarelo. Revista Brasileira de Armazenamento, Viçosa, v.27, n.1, p.30-35, 2002.

MOTA, W. F.; SALOMÃO, L. C. C.; CECON, P.R.; FINGER, F.L. Ceras e Embalagem Plástica na Conservação Pós-Colheita do MaracujáAmarelo. Scientia Agricola, Piracicaba, v.60, n. 1, p.51 - 57, 2003.

PEPELLENBOS, H.W.; TIJSKENS, L.M.M.; LEVEN, J.V.; WILKINSON, E.C. Modelling oxidative and fermentative carbon dioxide production of fruits and vegetables. Postharvest Biology and Technology, Amsterdan, v.9, p.283-295, 1996.

PESIS, E.; AHARONI, D.; AHARON, Z.; BEN-ARIE, R.; AHARONI, N.; FUCHS, Y. Modified atmosphere and modified humidity packaging alleviates chilling injury symptoms in mango fruit. Postharvest Biology and Technology, Amsterdan, v.19, p.93-101, 2000.

RESENDE, J.M.; VILAS BOAS, E.V.B.; CHITARRA, M.I.F. Uso de atmosfera modificada na conservação pós-colheita do maracujáamarelo. Ciência e Agrotecnologia, Lavras, v.25, n.1, p.159-168, 2001

ROBERTSON, G.L. Food packaging. New York: Marcel Dekker, 1993. $676 \mathrm{p}$.

SILVA, A.P.; VIEITES, R.L.; CEREDA, E. Conservação de maracujádoce pelo uso de cera e choque a frio. Scientia Agrícola, Piracicaba, v.56, n.4, 1999.

SOUSA, J.P.; PRAÇA, E.F.; ALVES, R.E.; BEZERRA NETO, F.; DANTAS, F.F. Influência do armazenamento refrigerado em associação com atmosfera modificada por filmes plásticos na qualidade de mangas 'Tommy Atkins'. Revista Brasileira de Fruticultura, Jaboticabal, v.24, n.3, 2002

WEATHERLEY, P.E. Studies in the water relations of cotton plant. I The field measurement of water deficits in leaves. New Phytologist, Cambridge, v.49, p.81-97, 1950.

ZAGORY, D.L.; KADER, A.A. Modified atmosphere packaging of fresh produce. Food Technology, Chicago, v.42, n.9, p.70-77, 1988. 